\title{
Strategy of Cross-culture intercultural communication in English teaching
}

\author{
Wenwen Guo
}

\author{
Zhengzhou university of industrial technology.Henan.China
}

Keywords: Cross-culture; intercultural communication; English teaching

\begin{abstract}
Language has emerged and has been developing together with its cross-culture and they have mutually dependent ever since the interdependent relations between language and cross-culture can be further explained in the following aspects. Historically languages have been together with the existence of the relevant cross-cultures. As we all know the origin of language is closely related to the origin of human beings.Around three million years when the productive forces were extremely low huge natural forces and fierce animals were great threats against the existence of human being so people had to cooperate and get together to form groups or tribes of different sizes to fight with nature. In this way, society came into being in which language was needed to communicate with among its members. This paper mainly concluded that the introduction of culture to English teaching is necessary, so that the effect of English teaching can be improved and smooth intercultural communication can be achieved.
\end{abstract}

\section{Introduction}

What does "cross-culture" mean? Samovar and Porter define it as "the cumulative deposit of knowledge, experience,beliefs, values, attitudes, meanings, hierarchies, religion, notions of time, roles, spatial relations, concepts of the universe, and material objects and possessions acquired by a group of people in the course of generations through individual and group striving". "language" is defined by some linguists as "a system of arbitrary vocal symbols used for human communication".We have to make clear above all what language is and what cross-culture is. Based on the theories in a Concise course on Linguìstics for students of English language to put it simply it is in essence a system of symbols designed for the purpose of human communication. It is a tool with which people convey their ideas emotions desires and so on. It is either spoken or written or both for communication. But the acquisition of a particular language is a cultural practice rather than a genetic one. It is learned or taught instead of biologically transmitted from generation to generation.

The relationship between language and cross-culture is dialectic. On the one hand, every language is part of a cross-culture. It serves and reflects cross-culture needs. For example, Eskimo has a rich vocabulary for different kinds of snow whereas English has only two. The fact that Eskimo boasts a large number of snow terms has a ready explanation in the important part snow plays in the life of the Eskimos. On the other hand, cross-culture influences language. For example, in English a sharper awareness of woman's need for independence has given currency to such term as "chairperson" and "spokesperson", and has helped to make the use of "their" in sentences like "Every one has to do their job properly" more acceptable, in preference to the male chauvinistic "his" and the clumsy "his or her". So, if a person wants to learn a language well, he or she should learn the cross-culture background related to the language.

Where there are people who will 1earn the language which is most widely used in the wor1d.As for cross-culture according to the Course it means the total way of life of people including the pattern of customs traditions social habits values beliefs and language of a society. It may have two divisions according to some linguistics theories. One refers to the active everyday patterns including the patterns of greetings thanks and compliments ways of address number taboos unique expressions etc. The other division is concerned with the patterns of politics education economics his religions etc. Of the two divisions the former is more important for a language student to know 
while the latter also plays an important role in promoting cultural understanding. Some cross-culture such as values and beliefs which are difficult to sense are more likely to cause problems to foreign language and 10 increase difficulty in inter-cultural communication.

Language has emerged and has been developing together with its cross-culture and they have mutually dependent ever since the interdependent relations between language and cross-culture can be further explained in the following aspects. Historically languages have been together with the existence of the relevant cross-cultures. As we all know the origin of language is closely related to the origin of human beings.Around three mil1ion years when the productive forces were extremely low huge natural forces and fierce animals were great threats against the existence of human being so people had to cooperate and get together to form groups or tribes of different sizes to fight with nature. In this way ,society came into being in which language was needed to communicate with among its members.As any tribe or society had its certain way of life-cross-culture we can see clearly that language from its stage was related to its cross-culture and they have been mutually dependent ever since.

The purpose of learning a foreign language is to use it as a tool to communicate with other nations, which makes the introduction of cross-culture to language teaching important. In China, the introduction of cross-culture to English teaching starts from the 1980s. One of its characteristics is that it is closely connected with China's modernization process and opening up and reform. Theprocess of modernization speeds up the exchange of products and thoughts with other foreign countries. The world is becoming smaller and smaller and even becoming a "global village". So, intercultural communication between different nations becomes a necessary part in people's life. However, cultural difference is the main impediment to intercultural communication. If one enterprise wants its products to enter international market or a transnational company wants to make benefits in many counties and regions, what they need is not only high technology and smart managing but also the knowledge of different cross-cultures. For example, in China "dragon" is the symbol of luck and power. Chinese feel proud as descendents of dragon. However, in western people do not have special feelings to dragon and even regard dragon as an ugly and threatening monster. If one company does not have this knowledge and puts theirproducts printed with dragon into international market, there is no doubt this company will fail to stimulate western people to buy their products. From this point of view, it is very necessary to learn cross-culture while learning English.

Situation of cross-culture Teaching in China

In china, the strong force driving students to study English is to pass entrance examinations for high schools and colleges. So, in most high schools the grammar- translation is still the most dominant method in English teaching. This method is grammar oriented, which means that teachers only emphasize the grammar and sentence structures in English teaching and ignore the introduction of cultural background of English-speaking countries. This way of teaching leads to the situations where most students, even those who have entered universities, have not attained a high level of English proficiency. A complaint by a native English teacher may provide us with a suggestion. She says, "They (students) depend on me to do everything. In most classes, they just sit there and I have to tell them to talk...” Her students probably are enthusiastic and eager to learn English, but the fact that the teacher and her students belong to different cross-cultures affects their teaching and learning negatively. This situation of English teaching in China worries many linguists. They insist that cross-culture should be taught in English teaching, so that the situation can be changed and English teaching can go effectively.

\section{Cross-culture teaching methods}

Based on my experience of learning English and the books I have read on cross-culture teaching and English teaching, I have got some ideas about how to teach cross-culture in English classroom and what kind of roles English teachers should play in the teaching. The ideas are only a small part of the whole cross-culture teaching, but I hope they can help to make the teaching of cross-culture a better experience for both teachers and students. 
There are many books that introduce methods of cross-culture teaching. Some linguists state eighteen successful methods of cross-culture teaching. I combine the methods I have got on books and my experience of learning English and then acquire two methods that I think are effective. One is the combination of language and cross-culture; the other is the method of discussing.

\section{A . Combination of cross-culture and Language}

This method supplies brief explanations or a guidance of cross-culture implications. It is important to combine language and cross-culture especially in vocabulary teaching. This is because some words have different connotations from cross-culture to cross-culture. For example, the words to describe energetic can be taken differently. Two years ago, I realized how the word "active" has a different connotation in Canada and in China. In China, "active" is in most cases a compliment, such as, in class if a student often answers questions voluntarily, then teachers can take he or she as "active". Therefore, I did not hesitate to say "You are active" to my male teacher who is Canadian when he was teaching us play a lot of games in class. The result of my words is that he was slightly embarrassed because "active" means "sexually active" in Canada. Fortunately, this incident is trivial. It is far better not to offend people. If I know this general difference I can avoid this to some extent.

Some languages have huge vocabularies in certain areas. For example, American has several words corresponding to "drunk" namely, "pissed”, "pickled”, "high", "bombed”, "stoned", "intoxicated". This is because cars are very common in America and driving after drinking probably causes big damage. Proverbs and sayings carry cultural connotations and meanings, too. One Chinese proverb goes "Silence is gold" meaning that silence is better or useful than eloquence. On the other hand, English proverb says "Squeaking wheels get oil" which means if you are quiet, you cannot receive anything. As we have seen, silence has different connotations in the U.S and China.There are also many other expressions in Chinese which have a lot to do with Chinese politics and economy and require relevant knowledge to understand them fully. For example:" separate the function of the Party from those of the government" to name just a few. Actually "Three-in-one" refers to cases where leading cadres technicians and workers in an enterprise pool their heads to solve questions of production and technology. Perhaps this explanation itself is also based on the Chinese cultural background. In English similarly you can see here and there a large number of expressions which contain much information about the Western culture. As English learners understand completely idioms without the necessary knowledge of English culture concerning dietetic habits and religious beliefs such as "The proof of the pudding is in the eating" "The mills of God and slowly" and "to cast pearls before a swine" etc. All these examples provide us with a suggestion that English teachers should pay attention to the combination of cross-culture and language and introduce cross-culture to vocabulary teaching and text explanations in English class.

\section{Method of Discussing}

When students have read an activity or listened to a story, teachers may like to use reformulation to allow them to check what they have learned and to reinforce it by retelling it to their partners. Reformulation simply means: "Explain what you just learned to your partner in your own words." It is a very simple technique, but has proved very successful for learning both cross-culture and language. Through reformulation, students check what they have learned, find out things that they have missed from their partners, and improve their language by noticing gaps in their own ability to explain.

As students watch a video or are engaged with some other materials, teachers can ask them to "notice" particular features. For example, they could watch a video of a target- cross-culture wedding and note all the differences with their own cross-culture and then discuss. Asking students to "notice" gives a focus on the materials by making it into task, rather than simply passive viewing or listening. Prediction can be a useful tool in quizzes, but it can also be equally useful in using almost any materials. Like "noticing”, prediction can engage the students more actively. For example, when teacher is telling a story, he or she can stop at a certain point and ask students to predict how it will continue. Or, when a teacher is giving out a reading for homework, first gives the title of the 
reading and asks students to predict what they will learn and discuss with their partners. This will force them to review their existing knowledge of the topic and raise their curiosity about whether their prediction is correct or not.

Student research is one of the most powerful tools that teachers can use with college students, because it combines their interests with the English class. For example, after the first class, teachers can ask students to search the Internet or library and find information on any aspects of the target-cross-culture that interests them. In the following class, students explain to their group what they have learned and answer any questions about it. This can lead to poster-sessions or longer projects. For some students, it can even lead to a long-term interest in the target-cross-culture.

Teacher's Roles in cross-culture Teaching

Can teacher's attitudes towards students and cross-culture learning in English class depend on each teacher? It goes without saying that every teacher has his or her own personality, aptitude and philosophy about English education. It is also true that teachers should be informed and trained linguistically and cross-culturally. Without formal instructions,teachers will end up depending upon their intuitions, previous knowledge and experiences. What should teachers do to have students appreciate different cross-cultures and expand their horizons without risking their identity and without oversimplifying or over generalizing their ideas towards different cross-cultures? Teachers should help students to realize that they can find their own third position between two cross-cultures, their native and second cross-culture. Then students will be objective to both cross-cultures. In order to convince students of this idea, teachers need to give sufficient information about cross-cultures. A Japanese linguist suggests the concept of third position. Teachers should teach students form their identity as the third position, so that they can accept that each cross-culture has its own norms and standards and they do not judge these norms and standards from their native cross-culture standpoints. Their standpoints are between their own cross-culture and the second cross-culture, therefore they can be less biased and prejudiced to both cross-cultures.

Teachers themselves also ought to learn cross-culture differences that interfere with smooth communication. Without knowing the differences, they are not fully able to give information to their students. They do not need to have experiences overseas, however, they are required to be good communicators among people from different cross-cultures. It can be suggested that English teachers-to-be might what to have cross-culture studies in the course of teacher training. Currently in China cross-culture learning is not compulsory for future teachers. So some current and future teachers may not know cultural differences between China and English speaking countries. If teachers do not know cultural differences that interfere with communication, are they less competent than those who have the knowledge? The answer is partly yes and partly no. As recent textbooks in China are inclined to select global issues such as starvation in Africa or Brazilian rain forest, teachers are bound to teach historical and cultural background no matter whether they have learned the cultural differences or not. However, teachers who have the knowledge of cross-cultures can provide extra systematic description and analysis that may grab students' attention. In addition, teachers with formal cross-culture learning experiences know what to teach, what to inform students.Therefore, future teachers have to learn different cross-cultures in a formal setting.

\section{CONCLUSION}

Earlier in this paper, we have seen that language and cross-culture are inseparable. So it is important to learn cross-culture while learning a language. Considering English and Chinese are two different language systems, introducing different cross-cultures and cultural tolerance is necessary so that learners can expand their horizons and come to accept differences. Negative feeling towards different groups will be reduced and more smooth communication will be achieved. In cross-culture teaching, teacher plays an important role, which does not mean that students can entirely depend on teachers to learn cross-culture in English class. Students themselves should also cultivate their interests in cross-culture learning. In this way, the introduction of cross-culture can really be effective and properly help to improve the effect of English teaching. 


\section{Reference}

[1]Brown, H.D. Principles of Language Learning and Teaching. New Jersey: Prentice-Hall, 1980, pp. 50-55.

[2] Hu Zhuanglin, Liu Renqing, Li Yanfu. Linguistics. Beijing: Beijing University Press, 1987, pp. 50-57.

[3] Kawano, M. 'Teaching Culture in English Class in Japan. http://www.ntu.edu.cn, 2000.

[4] Kramsch, C. Context and Culture in Language Teaching. London: Oxford, 1994, pp.73-78.

[5] Samovar, L.A. \& Porter, R.E. Communication Between Cultures. California: Wadsworth, 1995, pp.10-14.

[6] Stern, H.H. Issues \& Options in Language Teaching. London: Oxford,1996, pp. 12-20. 